\title{
Preface for the Steve White Honorary Issue of Neurochemical Research
}

\author{
Henrik Klitgaard ${ }^{1}$
}

Published online: 29 June 2017

(C) Springer Science+Business Media, LLC 2017

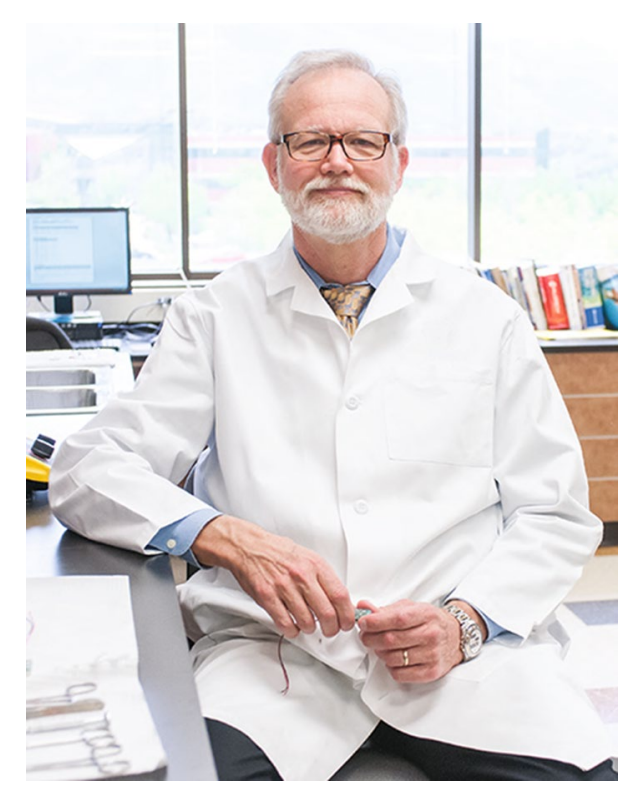

The opportunity to serve as Guest Editor for this special, honorary issue for Steve has been a huge privilege and great personal pleasure for me. I remain forever indebted to Pr. Arne Schousboe, Editor-In-Chief, for selecting me, and to Ms. Kristine Immediato and Ms. Divya Nagarajan for their patient, professional and invaluable help; allowing me to properly execute this task. It has also been very rewarding to receive the honor to be chosen as a contributor amongst the well-renowned invited scientists and colleagues of Steve. I am grateful to all the authors for

Henrik Klitgaard

Henrik.Klitgaard@ucb.com

1 New Medicines, UCB, Braine-L'Alleud, Belgium ensuring a high scientific level of this special, honorary issue for Steve.

I first met Steve in 1991, when he presented a poster during the annual American Epilepsy Society meeting. This initiated a long-lasting scientific dialogue and triggered an enduring friendship that matured over the years, and has expanded to include our families as well. While Steve's undisputed scientific merits are testified by publication of more than 200 full length papers, greater than 40 book chapters and numerous invited lectures at esteemed meetings, it never changed his humble and emphatic approach towards people. This attitude is what makes it a great pleasure to consider him a colleague and friend, but to also contribute to the respect and admiration that he so well deserves. 
Steve obtained a bachelor degree in pharmacy in 1977, and a M.Sc. in pharmacology in 1979; both from Idaho State University. He subsequently joined University of Utah as an NIH Predoctoral Trainee and Postdoctoral Fellow; the latter in the laboratory of the famous Pr. Dixon Woodbury. This was followed by an appointment as Assistant Professor (1987-1992) and Associate Professor (1992-2001), still at University of Utah, while also serving as Senior (1986-1995) and Principal Scientist (1995-2001) at the NINDS Anticonvulsant Screening Program (ASP). Following a sabbatical year at Johnson and Johnson in New Jersey from 2000 to 2001, Steve returned to the University of Utah and was appointed Professor at the Department of Pharmacology and Toxicology, and Director and Principal Investigator in the ASP. He held both positions from 2001 to 2016, during which his leadership and scientific excellence involved him in the discovery of several new AEDs, development of new animal models of epilepsy, and led to important research addressing pathophysiological mechanisms in the disease process of epilepsy. This was recognized by Steve receiving an honorary doctoral degree in Pharmaceutical Sciences (Dr. Pharm., h.c.) from the University of Copenhagen in 2011, the Lifetime Accelerator Award from the Epilepsy Foundation in 2014 and the Ambassador of Epilepsy Award from the International Bureau for Epilepsy and the International League Against Epilepsy in 2015. Steve was appointed Research Director for Citizens United for Research in Epilepsy (CURE) in 2011, which enabled him to pursue his strong passion for translational research that facilitate availability of new treatments to epilepsy patients with insufficient seizure control. In line with this, last year Steve accepted the position of Professor and Chair at the Department of Pharmacy at the University of Washington School of Pharmacy, which will enable him to continue focusing on translational work.

This special, honorary issue opens with a tribute to Steve from Pr. Emilio Perucca (Perucca, E, Neurochem Res, Special Issue for H. Steve White, 2017) [1], President of the International League Against Epilepsy that briefly reviews the outstanding career, scientific merits and unique contribution of Steve to the identification of new antiepileptic drugs (AEDs) that can improve the life of patients with epilepsy. The latter is emphasized by the second commentary from Pr. Harold Kohn (Kohn, H, Neurochem Res, Special Issue for H. Steve White, 2017) [2], the discoverer of Lacosamide, who praises Steve's leadership of pharmacological screening activities at the ASP resulting in the identification of the anticonvulsant properties of Lacosamide. Steve also holds a strong dedication to ensure that new research and therapies rapidly benefit patients, which is addressed and acknowledged by the last, and third, commentary by Susan Axelrod (Axelrod S, Neurochem Res, Special Issue for H. Steve White, 2017) [3], Founding Chair of CURE. This is followed by unique expert reviews of animal models of seizures and epilepsy, the history and achievements of the ASP, and the prospects and strategy of the ETSP. Finally, this issue also contains a number of original papers and brief reviews on various topics of contemporary epilepsy research.

Steve is not only unique by his scientific contributions and behavior, he is also one of the very rare scientists that have the good fortune to see their research materialize into new treatment options, improving patient's lives, and generating hope for so many others. For all of these reasons and more, this Special Issue is very timely and so well deserved.

Henrik Klitgaard, Ph.D.

Guest Editor

\section{References}

1. Perucca EA (2017) Tribute to Steve White: a commentary. Neurochem Res. doi:10.1007/s11064-016-2071-1

2. Kohn H (2017) H. Steve White: a champion for contemporary epilepsy research. Neurochem Res. doi:10.1007/ s11064-017-2180-5

3. Axelrod S (2017) Steve White: a hero for patients with epilepsy. Neurochem Res. doi:10.1007/s11064-017-2189-9 